\title{
A Theoretical Integration of Schema Therapy and Cognitive Therapy in OCD Treatment: Goals and Beliefs of the Obsessive Mind (Part I)
}

\author{
Olga Ines Luppino ${ }^{1 *}$, Katia Tenore ${ }^{1}$, \\ Francesco Mancini ${ }^{1,2}$, Barbara Basile ${ }^{1}$ \\ ${ }^{1}$ Association of Cognitive Psychology, School of Cognitive Psychotherapy, Rome, Italy \\ ${ }^{2}$ Marconi University, Rome, Italy \\ Email: *luppino@apc.it
}

How to cite this paper: Luppino, O. I., Tenore, K., Mancini, F., \& Basile, B. (2018). A Theoretical Integration of Schema Therapy and Cognitive Therapy in OCD Treatment: Goals and Beliefs of the Obsessive Mind (Part I). Psychology, 9, 2261-2277. https://doi.org/10.4236/psych.2018.99129

Received: July 2, 2018

Accepted: September 8, 2018

Published: September 11, 2018

Copyright (c) 2018 by authors and Scientific Research Publishing Inc. This work is licensed under the Creative Commons Attribution International License (CC BY 4.0).

http://creativecommons.org/licenses/by/4.0/

(c) (7) Open Access

\begin{abstract}
The present work is the first of a trilogy of articles whose purpose, as a whole, is to present a theoretical conceptualization of OCD functioning, which results from the integration between the Cognitive Therapy model, as proposed by Mancini (2018), and the Schema Therapy Mode model. In particular, this first paper aims to synthetically present the cognitive model of OCD functioning. According to the frame offered by Mancini, we will provide some evidence demonstrating the central role of deontological guilt and disgust as proximal psychological determinants in the genesis and maintenance of obsessive symptoms. The theoretical assumptions and the dynamics of the recursive processes at the basis of the maintenance of OCD will be clarified through a clinical exemplification and the clinical intervention goals will be presented. In order to plan an intervention on the experiences representing the historical vulnerability of OCD, the work also aims to present the important role played by particular kinds of early experiences in sensitizing to deontological guilt and disgust. To summarize, the current work presents the theoretical bases of a cognitive OCD conceptualization, in terms of goals and beliefs that are the drivers of obsessive behaviors. This introduction is preparatory to our proposal of integration between the cognitive model and the Schema Therapy Mode model that will be developed in the next two articles.
\end{abstract}

\section{Keywords}

Obsessive-Compulsive Disorder, Deontological Guilt, Disgust, Cognitive Therapy 


\section{Introduction}

This paper is the first of a trilogy of articles whose aim is to propose a conceptualization of the functioning of Obsessive Compulsive Disorder (OCD) resulting from the integration between the Cognitive Therapy (CT) framework, as proposed by Mancini (2018), and the Schema Therapy model (Young et al., 2003), in terms of Modes.

In this first work in particular we intend to present the cognitive model of OCD functioning, in terms of goals and beliefs that are the drivers of obsessive behaviors.

The paper synthetically presents a review of the numerous researches that have highlighted the role of the proximal psychological determinants in the genesis and maintenance of the obsessive symptomatology. First of all the emotion of guilt, in particular deontological guilt, secondly the emotion of disgust, whose close relationship with deontological guilt explains the co-occurrence in obsessive patients of fear of contamination and fear of guilt, and third the Not Just Right Experience (NJRE), also influenced by deontological guilt (Gangemi \& Mancini, 2017).

In order to better illustrate the dynamics of the recursive processes at the basis of the maintenance of the disturbance, the theoretical assumptions will be clarified through a clinical exemplification, synthesized in the presentation of the internal profile of the disorder as conceptualized by Mancini (2018), in the framework of clinical cognitivism.

With the aim of shedding light on the conditions of historical vulnerability that make OCD patients more predisposed to the development of the disorder, the work also aims to carry out an in depth analysis of the role played by specific types of early experiences, mainly relational, which render these patients sensitive to the themes of guilt, in particular deontological guilt, and of disgust. Early experiences seem to play an important role in this sense, more particularly the family atmosphere and certain educational patterns seem to constitute fertile ground for cognitive vulnerability to OCD (Tenore \& Basile, 2018).

In line with a therapeutic global approach to OCD, the bases of clinical cognitive intervention will be presented, starting from the two main therapeutic objectives: the first aimed at interrupting the recursive processes responsible for maintaining the disorder, the second aimed at reducing patients sensitivity toward guilt or the experience of disgust through a process of progressive acceptance of the feared threat.

As anticipated, the present work will be followed by two more: one (Tenore et al., 2018a) intends to provide the rationale of a possible integration between the CT model, that will be illustrated in this article, and a conceptualization according to Schema Therapy, in line with the work with Modes; the other (Basile et al., 2018a) intends to illustrate the experiential techniques used in Schema Therapy, integrated with some cognitive techniques, aimed at accepting the emotions of guilt and disgust. 


\section{The Proximal Determinants of Obsessive Symptomatology}

Within the frame of Appraisal Theories, OCD models claim that patients have specific goals (i.e., desires, needs, values) and beliefs (i.e., cognitions, representations, assumptions) that represent proximal determinants of behavior (Castelfranchi \& Paglieri, 2007). Appraisal theories assert that emotional states are based on the subjective evaluation/appraisal of the personal meaning and attribution of a specific event (Scherer, 1999). Within OCD, specific goals and beliefs represent the proximal psychological determinants of patient's symptoms. In this perspective compulsions are aimed at preventing or neutralizing the threat represented by the obsessive thoughts (Abramowitz, 2006).

What we suggest here (see also Mancini, 2018; Gangemi \& Mancini, 2017) is that the core goal of OCD patients is to prevent the feeling of guilty that he/she evaluates as unacceptable and grave. This is based on patients' assumption that one has the crucial power to prevent such threat from happening.

There is a great amount of literature that emphasizes the crucial role of guilt in OCD genesis and maintenance (Lopatcka \& Rachman, 1995; Shafran, 1997; Ladouceur et al., 1996; Vos et al., 2012). Also, other findings showed a strong positive association between obsessive symptom severity and higher guilt and responsibility rates (Freeston et al., 1993; Freeston et al., 1992; Frost et al., 1994; Ladouceur et al., 1995; Menzies et al., 2000; Rachman et al., 1995; Rhéaume et al., 1995a, 1995b; Salkovskis et al., 2000; Shafran et al., 1996; Steketee et al., 1998; Steketee et al., 1991; Wilson \& Chambless, 1999). Finally, neuroimaging studies showed an overlap between brain areas associated with guilt emotion processing (i.e., the anterior cingulate cortex, temporal poles, insulae and medial prefrontal cortex), and brain regions that are affected in OCD (Shin et al., 2000; Takahashi et al., 2004).

It also seems quite evident that decreasing the sense of perceived responsibility, attributing responsibility of the threatening event to someone else, dramatically reduces OCD patients' worry and anxiety (Lopatcka \& Rachman, 1995). This leads to the conclusion that patients do not fear the specific consequences of the dramatic event (as for instance, a gas explosion), but the fact that the main aspect is related to their own responsibility within the event itself. Similarly, some OCD patients are particularly worried about religious or sexual sins, where no one is involved nor damaged. That is, guilt feelings might arise even if no victim is involved! This kind of guilt seems to be quite different from a more relational kind of guilt that people usually experience when others they care about have been damaged because of them (Prinz \& Nichols, 2010).

Several studies point out that OCD patients particularly fear one specific kind of guilt emotion, originated by the assumption of having violated an internalized moral rule, such as, for instance, "having played God rule" if practicing euthanasia, even though it was aimed at reducing suffering and pain in a very ill person (Mancini et al., 2008). Deontological guilt is quite different from altruistic guilt, in which case there is a victim who is suffering-although not because of other's 
mistake. Moreover, in altruistic guilt, no moral rule has been violated.

Consistently, deontological and altruistic guilt rely on different neurobiological circuits involving disjointed brain areas (Basile et al., 2011). Some functional magnetic resonance imaging (fMRI) studies (Mataix-Cols et al., 2005; Rauch et al., 1998) have shown that obsessive patients undergoing a symptom provocation task show a similar activation (e.g., the anterior cingulate cortex and the insulae) as that activated in healthy subjects experiencing deontological guilt (Basile et al., 2011). In another fMRI study, Basile and colleagues (2013) showed that OCD patients confronted with deontological guilt-inducing stimuli, showed a decrease in blood oxygenation level dependent (BOLD) in specific brain areas (e.g., the anterior cingulate cortex, the insulae and the precuneus), when compared to healthy individuals undergoing the same emotional condition. Conversely, results revealed no differences between the two groups processing altruistic guilt, anger or sadness stimuli. A possible explanation for the reduced brain activation observed in OCD patients might depend on the "neural efficiency hypothesis" (Neubauer \& Fink, 2009), according to which a frequent exposure to specific conditions (in this case, deontological guilt feelings) corresponds to a decreased neural activation while processing such state. In a more recent study (Mancini \& Gangemi, 2015), OCD patients were confronted with Greene et al.'s (2001) moral dilemmas switch-version and authors found that, compared to healthy controls and other anxiety disorders, OCD patients were more prone to avoid deontological guilt choices (preferring omission choices, rather than action ones), than controls. All these data show quite univocally that guilt, and more in detail deontological guilt, plays a significant role in OCD.

According to Appraisal Theories, other two essential goals in OCD (on top of preventing deontological guilt) are to prevent or neutralize disgusting contamination (Rachman, 2006) and to avoid the Not Just Right Experience (NJRE-Coles et al., 2003), even if it not associated with or does not signal any damage for anyone. In the first case, it is well known that guilt and disgust share some common features (Lee \& Schwarz, 2011; Schnall et al., 2008). Additionally, several experiments showed that physical cleaning alleviates the distress associated with immoral behaviors, the so called "Macbeth Effect" (Zhong \& Liljenquist, 2006), which is more prominent in individuals with OCD, than in patients affected by other anxiety disorders (Reuven et al., 2013). As well, it has been shown that deontological guilt induction activates, more than altruistic guilt, washing behaviors (D'Olimpio \& Mancini, 2014). From an additional neurobiological view, disgust processing involves the insulae (Phillips et al., 2003), which are shown to be involved in deontological guilt processing (Basile et al., 2011). As well, within the OCD population, symptom severity and propensity for guilt and disgust have been found to be strongly associated (D'Olimpio et al., 2013). Finally, preliminary results of an ongoing study involving healthy participants (by our research group, in preparation) showed that moral-pride conditioning (i.e., environment-friendly actions) was significantly more effective in reducing 
physical disgust and self-disgust (Tobia, 2014), while exposed to disgusting stimuli, compared to self-efficacy conditioning (i.e., successful dieting or quit smoking). (These first data point to promising clinical interventions towards disgust-prone OCD patients.)

The NJRE, which his known as "the feeling that things are not the way they should be" (Coles et al., 2003; 2005), drives OCD patients to repeat their behavior (i.e., checking, ordering and performing symmetry rituals) until this negative feelings decreases. As a consequence, OCD patients try their best to avoid, reduce or neutralize such negative feeling. Some studies revealed a link between the NJRE and fear of guilt. More in detail, inducing guilt emotion increased the NJRE in non-clinical subjects (Mancini et al., 2008), and those with higher trait guilt reported more NJRE responses (in the State-NJRE survey questionnaire) and more severe OCD features, than subjects with low trait guilt.

\section{The Model of OCD Functioning in the Framework of Cognitive Therapy}

In line with the theoretical assumptions just mentioned, Mancini (2018) propose a model of understanding of OCD according to which obsessive symptoms are a consequence of specific evaluations that the subject makes of himself and of reality. It therefore follows that a precise and global understanding of the disorder cannot omit an analysis of the goals and representations through which the individual patient gives meaning to the events.

In order to better frame the functioning characteristics of the Obsessive Compulsive Disorder, as well as the goals and beliefs that constitute proximal determinants of the symptomatology, we will provide a clinical exemplification.

Mark, 25, single, economics student, lives at home with his parents. He spends his days performing a large number of rituals that take up most of his time, leaving him prey to a feeling of profound discomfort that alternates with violent crises of rage. The discomfort that Mark complains about is linked to the fear of being homosexual, a fear he tries to manage by engaging in repeated and exhausting operations of control and avoidance of thoughts and situations that might trigger doubt and consequently fear.

Mark cannot even spend a few hours without the doubt of being homosexual creeping into his mind; when walking along the street, for example, the simple acknowledgment of having laid eyes on a man triggers an internal dialogue in him that puts him in a state of alarm: "Why was I looking at him? Perhaps I like him? After all, I looked at him for some time... And what if this means I'm a homosexual? How disgusting! It would be terrible! I would be considered an outcast by everyone and lose my friends. Is it really possible that I am a homosexual? After all, until now I have only been attracted to women... It might sound implausible, but how can I rule this out with absolute certainty? I can't stand this doubt! I can't afford to overlook this possibility... I would be really guilty if I did...”. 
To contain the anxiety that overwhelms him and try to confute with absolute certainty even the slightest possibility that what he fears might occur, Mark engages in an intense activity of rumination through which, after having gone over every detail of the situation he found himself in, he tries, without success, to prove to himself, through dialectical reasoning and with absolute certainty, that what he fears cannot in any way be true.

Many hours of his day are spent trying to test his virility with a compulsive masturbatory activity following the viewing of heterosexual and homosexual sex videos; there are also frequent attempts to monitor his somatic sensations in order to better understand if what he feels, when viewing images of naked men, is or is not excitement.

He has also requested the opinion of health professionals (general practitioner, anthologist), and has asked them to confirm, with absolute certainty, that he is not homosexual and that he will never risk becoming one.

Along with the fear we have just described, which has afflicted Mark for over a year, for some time now there has also been an obsession about the possibility of causing serious damage due to carelessness, for example Mark is afraid of leaving the gas on, or forgetting to close the door of his home, or of losing his wallet.

In order to prevent the dreaded occurrence, Mark engages in prolonged control rituals: he checks his pockets several times or often returns home after leaving to see that the door is closed.

Because of his problems Mark is progressively choosing to spend more time at home, he sees his friends less and he has stopped training with his soccer team in order to avoid being exposed to his naked companions in the locker room; his university performance has become poor, he has difficulty studying because he says he cannot stay focused.

When asked by his therapist about his belief that his fears are grounded, Mark often replies that he realizes how absurd his thoughts are; the same question, however, receives an entirely different response when it is posed in a critical situation for him, which may be the moment he meets the gaze of a man.

Although he is aware of how much the problem is affecting his daily life, Mark claims he is not able to adequately contain and manage the disorder, experienced as something independent of his will and impossible to govern. He feels guilty towards his parents because he perceives that he is falling short of their expectations; he depicts them as being much more worried about his university performance than about his suffering.

He describes his mother as a rather cold woman, who raised him by giving him strict ethical and moral rules and often reproached him for every little mistake, worried about appearance and the judgment of people outside the family. His father, on the other hand, occupies a rather peripheral position, being often absent for work and basically complying, when present, with the maternal attitude.

Mark's symptomatology can be summarized in a diagram, see Figure 1, exemplifying the internal profile of the functioning of the disorder, as proposed by 


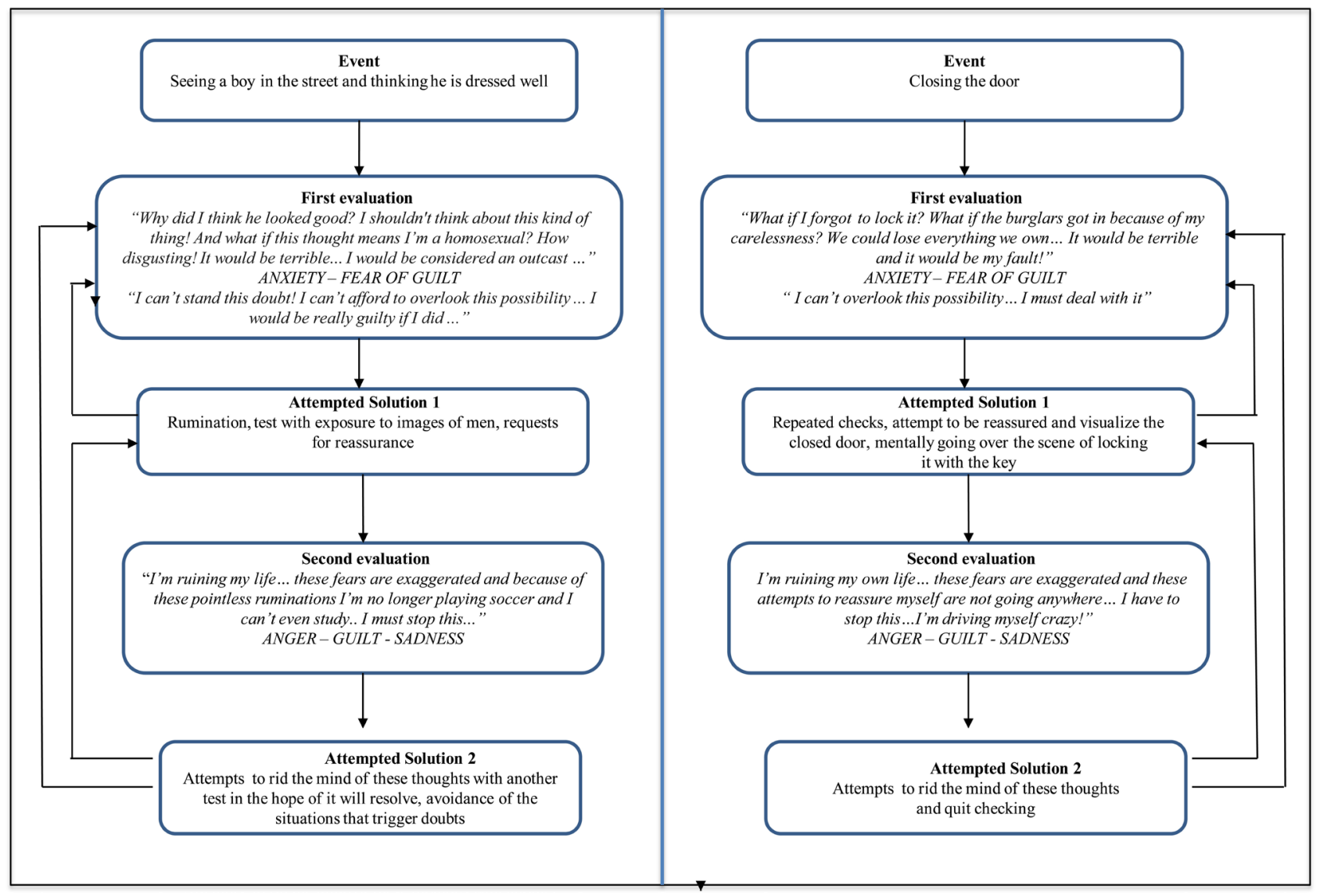

Figure 1. The internal profile of Mark's obsessive compulsive disorder is represented considering his two different symptomatic domains and their specific recursive processes.

\section{Mancini (2018).}

Regardless of the varying content of the obsessions, the diagram above highlights goals and beliefs of an obsessive mind. It represents a conceptualization of the obsessive dynamic and illustrates the vicious circles responsible for its maintenance. For most obsessive patients, as for Mark, it is possible to identify a critical event, which can be perceived by the patient, but also only remembered or hypothesized, and to which he attributes, in light of the first evaluation, the power to compromise one or more important objectives. The assessment of threat can be replaced by a sensation, such as NJRE; more generally, the symptomatology seems to be grounded in the fear of deontological guilt (Mancini, 2018). The perception of threat triggers in Mark the attempts to solve, a complex and mostly automatic reaction that consists of negative emotions (anxiety, guilt, disgust), cognitive processes (tendency to control hypothesis, selective attention and memory), mental attitudes (ruminations, mental compulsions) and behaviors (compulsions, avoidances, requests of reassurance) aimed at preventing or neutralizing the feared threat. As is evident in the diagram from the arrows exemplifying the recursive circles of the process, in obsessive patients this reaction actually proves to be paradoxically counterproductive, as it leads to the increase of events judged as threatening, increasing the feeling of probability, gravity and 
imminence of the perceived threat, thus reinforcing the objective of protecting oneself from it. To make the process more complex, the critical evaluation of Mark intervenes, which takes into consideration both the fears expressed in the first evaluation, judged as being exaggerated, and the first attempt to solve, carried out until that moment, the costs of which appear to be very high. This criticism is often degrading and guilt ridden, and is accompanied by negative emotions such as anger or sadness, and by the worsening of the symptomatology (Salkovskis, 1985). It is at this point in the process that Mark, in light of the high costs on which he is focusing, tries to contain the symptoms by means of a second attempt to solve, that can take the form of "contrasting" solutions (e.g. attempting to get rid of the thought) or "more than before" solutions (e.g. carry out a final and perfect test which may resolve the fears). Once again, both types of solutions, although effective in the short term, are clearly counterproductive because they are responsible, due to reinforcement mechanisms that act as vicious circles, of the maintenance of long-term symptoms.

More in detail, we can consider how Mark often tries to contain the disorder trying to rid his mind of the idea that he might be homosexual, an attempt which is responsible for a paradoxical effect known as "the white bear", or as "rebound effect" (Wegner et al., 1987) which causes the thought to becomes more frequent and persistent. Also, Mark can try to contain the problem by imparting to himself the paradoxical order to carry out a "last and definitive control", a solution that proves to be fallacious and counterproductive not only because it actually puts in motion a new sequence of controls, but also because it increases the negative evaluations the patient gives of himself in terms of failure, incapacity, weakness.

Summarizing, it is possible to identify, in the internal profile of OCD functioning, different recursive processes that maintain and worsen the disorder. Their reduction, as we will see later, represents one of the main objectives of the treatment aimed at achieving a significant decrease of the symptomatology. The reconstruction of the internal profile of the functioning, in the formulation presented here in the diagram, and sharing it with the patient, are the first steps to be taken. This important phase helps the patient to become aware of the functioning of his disorder and of the recursive circles that characterize the maintenance process. Providing information concerning the process functioning of the disorder, reducing the negative evaluation the patient has towards his own symptomatology, allows to create the conditions that favor a therapeutic alliance, laying the foundations for the planning of the intervention.

As a further goal, that generally comes after a first phase of work on recursive circles, it is necessary to try and make the patient less vulnerable to the disorder. An intervention that acts outside the symptomatic domain and focuses on memories, which may be historical or recent, which have rendered the patient sensitive to fear of guilt, can be extremely useful in this sense, reducing vulnerability for the problem as well as the risk of relapse. 


\section{The Role of Early Experiences with Respect to Vulnerability to OCD}

As is widely agreed on in the mental health field, the development of a pathology is not determined by a single factor, but is the outcome of a chain of events that include both distal factors, which act as direct causes, and proximal factors that are located previous to the problem and act through a series of mediating factors (WHO, 2013). When we talk about vulnerability we intend to refer to all those factors of weakness that can favor the development of a disorder. Analyzing the specific vulnerability of patients with OCD, in light of the theoretical assumptions already discussed, necessarily leads us to investigate what types of experiences have made these subjects particularly sensitive to the possibility of being guilty and / or of coming into contact with substances that are disgusting to the point that they must protect themselves at all costs.

Where does the need to prevent exactly these specific conditions arise from in these patients? What life experiences contribute, in these subjects, to such a catastrophic representation of guilt, in particular deontological guilt?

What we know from literature is that interpersonal context, the family atmosphere and certain educational styles, can be a breeding ground for cognitive vulnerability to OCD. Although the studies demonstrating this are nor numerous, early experiences play a fundamental role in determining the dysfunctional beliefs underlying the obsessive symptomatology, which may or may not develop depending on whether one or more stressful events trigger such sensitivity. From what emerges from the clinical observation and life history of these obsessive patients, their family members generally have rigid beliefs, mostly related to exaggerated responsibility and overestimation of threat; this effect is greater in the family members of OCD patients with an early onset (Tenore \& Basile, 2018). The family atmosphere is described as being markedly attentive to morality and normative behavior, tending to disapprove the child's behavior. More in particular, the parental reaction to the transgression of a rule is often not clear and incongruous, and sometimes occurs together with emotional distance and a particular facial expression being characterized by along and scornful face (Tenore \& Basile, 2018). Recent research by Basile and colleagues (2018b) highlights how the experience of parental blame and reproach is more present in the memories of obsessive patients, than in those of other types of patients. Such a passive-aggressive attitude, on the part of the parent, does not convey to the child only that a certain behavior is inappropriate, but also communicates a sense of general unacceptability as a person, threatening the continuity of the relationship with the caring figure. It is easy to understand how such a serious threat may act as driving factor behind the motivation, typically obsessive, to behave impeccably, anticipating any shortcoming and responsibility. To this one must add hypercontrol, criticism and the high parenting standards, responsible for creating perfectionist beliefs in children, on the basis of which the deviation from the strict standards determines the feeling of being guilty, caused by the 
perception that one is not up to these standards, and that one has disappointed such an expectation thus causing a parent to suffer.

Less numerous researches have studies in depth the ways in which a person may become sensitive disgust. It would seem that the most frequent way in which a child learns new eliciting factors of disgust is through a parent-child "transmission" (Rozin et al., 2000; Tomkins, 1963). Starting from an encounter with a particular stimulus on the part of the child, the parent can react with a specific expression, also vocal or verbal, of disgust, or with a behavior aimed at removing the child from the stimulus. If we consider the fact that in adults the observation of facial expression of disgust involves a pattern of neural activity that can be superimposed on that of actually coming into contact with a disgusting object (Wicker et al., 2003), the interpretation of the parental expression in response to certain stimuli may cause a facial mimic response of disgust able to induce in the child a feeling of disgust for these same stimuli (Rozin \& Fallon, 1987; Tomkins, 1963). In a study by Rozin and collaborators (2000), it emerged that the children of parents who are particularly reactive to stimulating eliciting basic disgust, are very reactive also to stimuli eliciting moral disgust; this supports the idea that the sensitivity of the parent to disgust plays an important role with respect to the formation of answers inherent to moral stimuli, which are connected to the risk of experiencing deontological guilt. Moral disgust, moreover, with respect to physical disgust, presents more relational connotations, and perceiving oneself as morally disgusting could be connected to the perception of a threat with respect to the continuity of the relationship with the other. Some research data (Enholt et al., 1999) have shown that patients with OCD report a fear of being judged negatively and, more particularly, of being the object of disgust and contempt on the part of others because of their mistakes. Faced with expressions of contempt and rage, which well translate the interpersonal consequences of deontological guilt (Basile \& Mancini, 2011), obsessive patients react with dramatically important emotional distress; they are particularly sensitive to accusations and contemptuous criticism because of their faults, real or feared. These subjects, much more than others, expect that if their fears were to come true (e.g. in the case of Mark, if he were really homosexual) they would find themselves confronted by an expressions of angry contempt, for them a source of profound suffering.

As illustrated above, obsessive patients are often worried about committing sins or moral violations, and not achieving the objective of preventing deontological guilt is perceived by these subjects as being a catastrophe, something that is unforgivable and unimaginable. Such a state of mind orients in a very peculiar way the cognitive processes with which these subjects process the information regarding danger and that regarding safety, with which they evaluate the outcomes of their own attempts to solve. Concerned that they might be guilty, obsessive patients aim to reach a double certainty: that of not having failed in their duty and of not having irresponsibly underestimated the threat of guilt, and of 
not having used the resources in an approximate way to prevent guilt. What seems to characterize people with OCD is therefore the fact that they do not consider moral mistakes as something that is basically human and thus unavoidable (Mancini \& Saliani, 2013).

\section{The Rationale of the Intervention: The Central Role of Accepting the Feared Threat}

As already anticipated, in planning the treatment of a patient with obsessive compulsive disorder it is important to have a clear understanding of the mechanisms of functioning of the disorder, the determinants of the patient's behavior, the factors responsible for the maintenance of the symptomatology, the experiences that contributed to the structuring of the sensitivity of the patient to guilt and his /her predisposition to feeling morally contemptible.

There are two main strategic objectives in the treatment of the OCD: the interruption, or more realistically, the reduction of the vicious processes underlying the maintenance of the symptomatology and the work to reduce the patient's vulnerability, mainly attributable to his/her general sensitivity to deontological guilt which leads him/her to consider faults, that would normally be considered highly unlikely or otherwise not particularly serious, to be catastrophic and unacceptable.

In a first phase there is a tendency to proceed by intervening with the aim of interrupting or reducing the maintenance processes, while the intervention aimed at reducing vulnerabilities is generally carried out at a later time, after a first improvement of the symptomatology. In most cases, in fact, the patient is so absorbed by the pervasiveness of the symptoms that he/she cannot accept to move away from them to work on the more general feeling of guilt. It is possible, however, that after a first and substantial symptomatic improvement the patient's sensitivity to guilt and his/her tendency to catastrophize such experiences is still very intense, so as not to favor an adequate stabilization of the results achieved and thus increasing the risk of possible future relapses. Several works (Consentino et al., 2012; Cosentino \& Mancini, 2012; Perdighe \& Mancini, 2012; Vos et al., 2012) suggest that the intervention on vulnerability alone, without working on recursive processes, is able to produce a clinically significant reduction in obsessive symptomatology. In line with this view, Veale and colleagues (2015) demonstrated the effectiveness, in terms of symptomatic reduction, of a single Imagery with Rescripting session targeting memories of faults connected to the domain of symptoms. A small pilot study (Consentino et al., 2012) also found a significant reduction in the obsessive symptomatology, also in the follow up carried out one year after the intervention aimed at decatastrophizing and accepting guilt feelings, which occurred in the daily life of patients outside the symptomatic domain, without intervening on the symptoms. More recently a research still underway, of which preliminary data are known (Tenore et al., 2018b), suggests that an experiential work that uses only the technique of Im- 
agery with Rescripting of episodes of early guilt, produces a clinically significant reduction of obsessive symptoms in a good percentage of patients. As we have already seen the possibility of being guilty in a deontological sense is experienced as an unacceptable and catastrophic experience by obsessive patients and this seems to depend on early experiences of reproach, perceived as being very dramatic and thus often traumatic. Therefore, the treatment of OCD cannot be carried out without also working on reduction of the dramatic aspect these subjects experience when perceiving themselves as potentially liable to deontological guilt. Attention to vulnerability factors has the goal of achieving a re-attribution of the meanings associated with early experiences, in terms of a sense of self and expectations of others. These psychological factors risk, if not modified by the therapeutic process, rendering the relapse of symptoms more probable, which is why it is essential to restructure the expectation of rejection in case of error, in order to replace the belief that making a mistake is a catastrophic event with the perception of having the same right as others to make mistakes, and that this will not result in dramatic relational consequences such as disruption of the relationship. It is very important to stress that the intervention is aimed at a decrease of sensitivity to guilt, which is not obtained by enhancing the patient's irresponsibility, or by pointing to the possibility that it might be someone else's fault; indeed the intervention must lead towards the acceptance of the possibility of being guilty.

\section{Conclusion}

To conclude, the present work proposes to present the model of conceptualization of OCD functioning as proposed by Mancini (2018) through the analysis of the numerous research outcomes that highlight the role of guilt, disgust and NJRE as proximal psychological determinants of obsessive symptomatology. Findings support the idea that guilt, and more specifically deontological guilt, is related to disgust sensitivity and to the NJRE, with all of them being particularly relevant in OCD pathology. In fact, obsessive patients seem particularly sensitive to the experience of guilt, experienced as catastrophic, unacceptable and unbearable. An important role in terms of sensitization to this type of experience seems to be played by the early experiences of reproach by the parental figures, experienced by the patient with extreme drama to the point they sometimes constitute traumatic experiences; clinical practice as well as recent work shows that in the history of obsessive patients there generally are memories of a family atmosphere that is particularly sensitive to morality and tending to severely punish the transgression of a rule. This type of experience constitutes a terrain of historical vulnerability, able to favor the typically obsessive tendency to behave in an impeccable manner, in an attempt to avoid the threat of guilt and the possibility of being despised. In light of the theoretical assumptions just mentioned, the treatment has two main strategic objectives: the interruption of the vicious processes underlying the maintenance of symptoms and the reduction of vulne- 
rability to guilt. In particular, we suggest that preventing deontological guilt might represent the common goal in treating OCD patients. This suggests that treatment of such emotional state, especially understanding and intervening on its vulnerability factors, and guilt acceptance might represent some fundamental targets of OCD therapy.

This work is the first of a trilogy of articles that aim to present a proposal for integration between the CBT model illustrated here and a conceptualization in Schema Therapy according to the work with Modes. The work of Tenore and colleagues (2018a) will illustrate in detail the proposed integration model, providing the rationale; the work of Basile and collaborators (2018a) will instead present the application of the main experiential techniques used in Schema Therapy integrated with some cognitive type techniques, for an intervention aimed at accepting the emotions of guilt and disgust.

\section{Conflicts of Interest}

The authors declare no conflicts of interest regarding the publication of this paper.

\section{References}

Abramowitz, J. S. (2006). Understanding and Treating Obsessive-Compulsive Disorder. A Cognitive-Behavioral Approach. Mahwah, NJ: Lawrence Erlbaum Associates Inc.

Basile, B., \& Mancini, F. (2011). Eliciting Guilty Feelings: A Preliminary Study Differentiating Deontological and Altruistic Guilt. Psychology, 2, 98-102.

https://doi.org/10.4236/psych.2011.22016

Basile, B., Fadda, S., De Sanctis, B., Saliani, A. M., Perdighe, C., Luppino, O. I., Tenore, K., \& Mancini, F. (2018b). Early Life Experiences in OCD and Other Disorders: A Retrospective Observational Study Using Imagery with Re-Scripting Characterize OCD, But Not Other Disorders. Clinical Neuropsychiatry. [In Press]

Basile, B., Luppino, O. I., Mancini, F., \& Tenore, K. (2018a). An Integration of Schema and Cognitive Therapy in OCD Treatment: Experiential Techniques and Cognitive Based Interventions (Part III). Psychology, 9, 2296-2311. https://doi.org/10.4236/psych.2018.99130

Basile, B., Mancini, F., Macaluso, E., Caltagirone, C., \& Bozzali, M. (2013). Abnormal Processing of Deontological Guilt in Obsessive-Compulsive Disorder. Brain Structure and Function, 4, 1-11.

Basile, B., Mancini, F., Macaluso, E., Caltagirone, C., Frackoviack, R., \& Bozzali, M. (2011). Deontological and Altruistic Guilt: Evidence for Neurobiological Different Substrates. Human Brain Mapping, 32, 229-239. https://doi.org/10.1002/hbm.21009

Castelfranchi, C., \& Paglieri, F. (2007). The Role of Beliefs in Goal Dynamics: Prolegomena to a Constructive Theory of Intensions. Synthese, 155, 237-263. https://doi.org/10.1007/s11229-006-9156-3

Coles, M. E., Frost, R. O., Heimberg, R. G., \& Rhéaume, J. (2003). "Not Just Right Experiences": Perfectionism, Obsessive-Compulsive Features and General Psychopathology. Behaviour Research and Therapy, 41, 681-700.

https://doi.org/10.1016/S0005-7967(02)00044-X

Coles, M. E., Heimberg, R. G., Frost, R. O., \& Steketee, G. (2005). Not Just Right Expe- 
riences and Obsessive-Compulsive Features: Experimental and Self-Monitoring Perspectives. Behaviour Research and Therapy, 43, 153-167.

https://doi.org/10.1016/j.brat.2004.01.002

Consentino, T., D’Olimpio, F., Perdighe, C., Romano, G., Saliani, A. N., \& Mancini, F. (2012). Acceptance of Being Guilty in the Treatment of Obsessive-Compulsive Disorder. Psicoterapia Cognitiva e Comportamentale, 39-56.

Cosentino, T., \& Mancini, F. (2012). “Do I Love Her or Not?!” Intervention on Fear of Being Despised: An Obsessive-Compulsive Disorder Case Presentation. Psicoterapia Cognitiva e Comportamentale, 18, 199-213.

D’Olimpio, F., Cosentino, T., Basile, B., Tenore, K., Gragnani, A., \& Mancini, F. (2013). Obsessive-Compulsive Disorder and Propensity to Guilt Feeling and to Disgust. Clinical Neuropsychiatry, 10, 20-39.

D'Olimpio, F., \& Mancini, F. (2014). Role of Deontological Guilt in Obsessive-Compulsive Disorder Like Checking and Washing Behaviors. Clinical Psychological Science, 2, 727-739. https://doi.org/10.1177/2167702614529549

Enholt, K. A., Salkovskis, P. M., \& Rimes, K. A. (1999). Obsessive-Compulsive Disorder, Anxiety Disorders and Self-Esteem: An Exploratory Study. Behaviour Research and Therapy, 37, 771-781. https://doi.org/10.1016/S0005-7967(98)00177-6

Freeston, M. H., Ladouceur, R., Gagnon, F., \& Thibodeau, N. (1993). Beliefs about Obsessional Thoughts. Journal of Psychopathology and Behavioural Assessment, 15, 1-21. https://doi.org/10.1007/BF00964320

Freeston, M. H., Ladouceur, R., Thibodeau, N., \& Gagnon, F. (1992). Cognitive Intrusions in a Non-Clinical Population: II. Associations with Depressive, Anxious, and Compulsive Symptoms. Behaviour Research and Therapy, 30, 263-271. https://doi.org/10.1016/0005-7967(92)90072-O

Frost, R. O., Steketee, G., Cohn, L., \& Griess, K. (1994). Personality Traits in Subclinical and Non Obsessive Compulsive Volunteers and Their Parents. Behaviour Research and Therapy, 32, 47-56. https://doi.org/10.1016/0005-7967(94)90083-3

Gangemi, A., \& Mancini, F. (2017). Obsessive Patients and Deontological Guilt: A Review. Psychopathology Review, 4, 155-168. https://doi.org/10.5127/pr.045916

Greene, J. D., Sommerville, R. B., Nystrom, L. E., Darley, J. M., \& Cohen, J. D. (2001). An fMRI Investigation of Emotional Engagement in Moral Judgment. Science, 293, 2105-2108. https://doi.org/10.1126/science.1062872

Ladouceur, R., Leger, E., Rhéaume, J., \& Dube, D. (1996). Correction of Inflated Responsibility in the Treatment of Obsessive-Compulsive Disorder. Behaviour Research and Therapy, 34, 767-774. https://doi.org/10.1016/0005-7967(96)00042-3

Ladouceur, R., Rhéaume, J., Freeston, M. H., Aublet, F., Jean, K., Lachance, S., Langlois, F., \& De Pokomandy-Morin, K. (1995). Experimental Manipulations of Responsibility: An Analogue Test for Models of Obsessive Compulsive Disorder. Behaviour Research and Therapy, 33, 937-946. https://doi.org/10.1016/0005-7967(95)00024-R

Lee, S. W. S., \& Schwarz, N. (2011). Cleans Late Effects: The Psychological Consequences of Physical Cleansing. Current Directions in Psychological Science, 20, 307-311. https://doi.org/10.1177/0963721411422694

Lopatcka, C., \& Rachman, S. (1995). Perceived Responsibility and Compulsive Checking: An Experimental Analysis. Behaviour Research and Therapy, 33, 673-684. https://doi.org/10.1016/0005-7967(94)00089-3

Mancini, F. (2018). The Obsessive Mind. Abingdon-on-Thames: Routledge.

Mancini, F., \& Gangemi, A. (2015). Deontological Guilt and Obsessive Compulsive Dis- 
order. Journal of Behavior Therapy and Experimental Psychiatry, 49, 157-163. https://doi.org/10.1016/j.jbtep.2015.05.003

Mancini, F., \& Saliani, A. (2013). Senso di colpa deontologico e perdono di sé nel disturbo ossessivo-compulsivo. In B. Barcaccia, \& F. Mancini (Eds.), Teoria e clinica del perdono (pp. 131-144). Milano: Raffaello Cortina Editore.

Mancini, F., Gangemi, A., Perdighe, C., \& Marini, C. (2008). Not Just Right Experience: It Is Influenced by Feelings of Guilt? Journal of Behavior Therapy and Experimental Psychiatry, 39, 162-176. https://doi.org/10.1016/j.jbtep.2007.02.002

Mataix-Cols, D., Rosario-Campos, M. C., \& Leckman, J. F. (2005). A Multidimensional Model of Obsessive-Compulsive Disorder. American Journal of Psychiatry, 162, 228-238. https://doi.org/10.1176/appi.ajp.162.2.228

Menzies, R. G., Harris, L. M., Cumming, S. R., \& Einstein, D. A. (2000). The Relationship between Inflated Personal Responsibility and Exaggerated Danger Expectancies in Obsessive Compulsive Concerns. Behaviour Research and Therapy, 38, 1029-1037. https://doi.org/10.1016/S0005-7967(99)00149-7

Neubauer, A. C., \& Fink, A. (2009). Intelligence and Neural Efficiency. Neuroscience \& Biobehavioral Reviews, 33, 1004-1023. https://doi.org/10.1016/j.neubiorev.2009.04.001

Perdighe, C., \& Mancini, F. (2012). Dall'investimento alla rinuncia: Favorire l'accettazione in psicoterapia. Cognitivismo Clinico, 9, 116-134.

Phillips, M. L., Drevets, W. C., Rauch, S. L., \& Lane, R. (2003). Neurobiology of Emotion Perception I: The Neural Basis of Normal Emotion Perception. Biological Psychiatry, 54, 504-514. https://doi.org/10.1016/S0006-3223(03)00168-9

Prinz, J., \& Nichols, S. (2010). Moral Emotions. In J. Doris (Ed.), Moral Psychology Handbook (pp. 111-148). Oxford: Oxford University Press. https://doi.org/10.1093/acprof:oso/9780199582143.003.0005

Rachman, S. (2006). Fear of Contamination: Assessment and Treatment. New York: Oxford University Press Inc. https://doi.org/10.1093/med:psych/9780199296934.001.0001

Rachman, S., Thordarson, D. S., Shafran, R., \& Woody, S. R. (1995). Perceived Responsibility: Structure and Significance. Behaviour Research and Therapy, 33, 779-784. https://doi.org/10.1016/0005-7967(95)00016-Q

Rauch, S. L., Dougherty, D. D., Shin, L. M., Alpert, N. M., Manzo, P., Leahy, L. et al. (1998). Neural Correlates of Factor-Analyzed OCD Symptom Dimensions: A PET Study. CNS Spectrums, 3, 37-43. https://doi.org/10.1017/S1092852900006167

Reuven, O., Liberman, N., \& Dar, R. (2013). The Effect of Physical Cleaning on Threatened Morality in Individuals with Obsessive-Compulsive Disorder. Clinical Psychological Science, 2, 224-229. https://doi.org/10.1177/2167702613485565

Rhéaume, J., Freeston, M. H., Dugas, M. J., Letarte, H., \& Ladouceur, R. (1995a). Perfectionism, Responsibility and Obsessive Compulsive Symptoms. Behaviour Research and Therapy, 33, 785-794. https://doi.org/10.1016/0005-7967(95)00017-R

Rhéaume, J., Ladouceur, R., Freeston, M. H., \& Letarte, H. (1995b). Inflated Responsibility and Its Role in OCD. Validation of a Theoretical Definition of Responsibility. Behaviour Research and Therapy, 33, 159-169. https://doi.org/10.1016/0005-7967(94)E0021-A

Rozin, P., \& Fallon, A. E. (1987). A Perspective on Disgust. Psychological Review, 94, 23-41. https://doi.org/10.1037/0033-295X.94.1.23

Rozin, P., Haidt, J., \& McCauley, C. R. (2000). Disgust. In M. Lewis, \& J. Haviland-Jones (Eds.), Handbook of Emotions (2nd ed., pp. 673-653). New York: Guilford Press.

Salkovskis, P. M. (1985). Obsessional-Compulsive Problems: A Cognitive-Behavioural 
Analysis. Behaviour Research and Therapy, 28, 571-588.

https://doi.org/10.1016/0005-7967(85)90105-6

Salkovskis, P. M., Wroe, A. L., Gledhill, A., Morrison, N., Forrester, E., \& Richards, C. (2000). Responsibility Attitudes and Interpretations Are Characteristic of Obsessive-Compulsive Disorder. Behaviour Research and Therapy, 38, 347-372. https://doi.org/10.1016/S0005-7967(99)00071-6

Scherer, K. R. (1999). Appraisal Theory. In T. Dalgleish, \& M. Power (Eds.), Handbook of Cognition and Emotion (pp. 637-663). Chichester, New York: Wiley. https://doi.org/10.1002/0470013494.ch30

Schnall, S., Haidt, J., Clore, G. L., \& Jordan, A. H. (2008). Disgust as Embodied Moral Judgment. Personality and Social Psychology Bulletin, 34, 1096-1109. https://doi.org/10.1177/0146167208317771

Shafran, R. (1997). The Manipulation of Responsibility in Obsessive-Compulsive Disorder. British Journal of Clinical Psychology, 36, 397-407. https://doi.org/10.1111/j.2044-8260.1997.tb01247.x

Shafran, R., Watkins, E., \& Charman, T. (1996). Guilt in Obsessive-Compulsive Disorder. Journal of Anxiety Disorders, 10, 509-516. https://doi.org/10.1016/S0887-6185(96)00026-6

Shin, L. M., Dougherty, D. D., Orr, S. P., Pitman, R. K., Lasko, M., Macklin, M. L., Alpert, N. M., Fischman, A. J., \& Rauch, S. L. (2000). Activation of Anterior Paralimbic Structures during Guilt Related Script-Driven Imagery. Biological Psychiatry, 48, 43-50. https://doi.org/10.1016/S0006-3223(00)00251-1

Steketee, G., Frost, R. O., \& Cohen, I. (1998). Beliefs in Obsessive-Compulsive Disorder. Journal of Anxiety Disorder, 12, 525-537. https://doi.org/10.1016/S0887-6185(98)00030-9

Steketee, G., Quay, S., \& White, K. (1991). Religion and Guilt in OCD Patients. Journal of Anxiety Disorders, 5, 359-367. https://doi.org/10.1016/0887-6185(91)90035-R

Takahashi, H., Yahata, N., Koeda, M., Matsuda, T., Asai, K., \& Okubo, Y. (2004). Brain Activation Associated with Evaluative Processes of Guilt and Embarrassment: An fMRI Study. Neuroimage, 23, 967-974. https://doi.org/10.1016/j.neuroimage.2004.07.054

Tenore, K., \& Basile, B. (2018). The Hystorical Vulnerability in OCD. In F. Mancini (Ed.), The Obsessive Mind. Abingdon-on-Thames: Routledge.

Tenore, K., Basile B., Mancini, F., \& Luppino, O. I. (2018a). An Integration of Schema and Cognitive Therapy in OCD Treatment: Theoretical Conceptualization and Rationale (Part II). Psychology, 9, 2278-2295. https://doi.org/10.4236/psych.2018.99129

Tenore, K., Basile, B., Cosentino, T., De Sanctis, B., Fadda, S., Gragnani, A., Luppino, O. I., Perdighe, C., Romano, G., Saliani, A. M., \& Mancini, F. (2018b). Efficacy of Imagery with Rescripting in Treating OCD: A Single Case Series Experimental Design (Preliminary Results).

Tobia, K. P. (2014). The Effects of Cleanliness and Disgust on Moral Judgment. Philosophical Psychology, 28, 556-568. https://doi.org/10.1080/09515089.2013.877386

Tomkins, S. (1963). Affect/Imagery/Consciousness Vol. 2, The Negative Affects. New York: Springer.

Veale, D., Page, N., Woodward, E., \& Salkovskis, P. (2015). Imagery Rescripting for Obsessive Compulsive Disorder: A Single Case Experimental Design in 12 Cases. Journal of Behavior Therapy and Experimental Psychiatry, 49, 230-236. https://doi.org/10.1016/j.jbtep.2015.03.003

Vos, S. P. F., Huibers, M. J. H., \& Arntz, A. (2012). Experimental Investigation of Target- 
ing Responsibility versus Danger in Cognitive Therapy of Obsessive-Compulsive Disorder. Depression and Anxiety, 29, 629-637. https://doi.org/10.1002/da.21915

Wegner, D. M., Schneider, D., Carter, S., \& White, T. (1987). Paradoxical Effects of Thought Suppression. Journal of Personality and Social Psychology, 53, 5-13. https://doi.org/10.1037/0022-3514.53.1.5

Wicker, B., Keysers, C., Plailly, J., Royet, J. P., Gallese, V., \& Rizzolatti, G. (2003). Both of Us Disgusted in My Insula: The Common Neural Basis of Seeing and Feeling Disgust. Neuron, 40, 655-664. https://doi.org/10.1016/S0896-6273(03)00679-2

Wilson, K. A., \& Chambless, D. L. (1999). Inflated Perceptions of Responsibility and Obsessive-Compulsive Symptoms. Behaviour Research and Therapy, 37, 325-335. https://doi.org/10.1016/S0005-7967(98)00146-6

World Health Organization WHO (2013). Research for Universal Health Coverage: World Health Report 2013.

Young, J. E., Klosko, J., \& Weishaar, M. E. (2003). Schema Therapy: A Practitioner's Guide. New York: Guilford Press.

Zhong, C. B., \& Liljenquist, K. (2006). Washing away Your Sins: Threatened Morality and Physical Cleansing. Science, 313, 1451-1452. https://doi.org/10.1126/science.1130726 